Post-print version: final draft post-refereeing (released with a Creative Commons Attribution NonCommercial No Derivatives License).

Bobes-Jesus, V., Pascual-Muñoz, P., Castro-Fresno, D., Rodriguez-Hernandez, J. (2013) Asphalt solar collectors: A literature review. Applied Energy (ISSN 0306-2619), Volume 102, February 2013, Pages 962-970.

http://dx.doi.org/10.1016/j.apenergy.2012.08.050

http://www.sciencedirect.com/science/article/pii/S030626191200637X

\title{
Asphalt solar collectors: a literature review
}

Vanesa Bobes-Jesus ${ }^{a}$, Pablo Pascual-Muñoz ${ }^{b}$, Daniel Castro-Fresnoc*, Jorge Rodriguez-Hernandez ${ }^{\mathrm{d}}$

${ }^{a}$ MSc Civil Engineer and PhD. Student, Dept. of Transport and Technology of Projects and Processes, ETSICCP, University of Cantabria, 39005 Santander, Spain. E-mail: vanesa.bobes@alumnos.unican.es

${ }^{b}$ MSc Mechanical Engineer and PhD. Student, Dept. of Transport and Technology of Projects and Processes, ETSICCP, University of Cantabria, 39005 Santander, Spain. E-mail: pablo.pascualm@unican.es

${ }^{c}$ Professor, Dept. of Transport and Technology of Projects and Processes, ETSICCP, University of Cantabria, 39005 Santander, Spain.E-mail: daniel.castro@unican.es

d Assistant Professor, Dept. of Transport and Technology of Projects and Processes, ETSICCP, University of Cantabria, 39005 Santander, Spain.E-mail: jorge.rodriguez@unican.es

\section{Abstract}

Asphalt pavements subject to solar radiation can reach high temperatures causing not only environmental problems such as the heat island effect on cities but also structural damage due to rutting or hardening as a result of thermal cycles. Asphalt solar collectors are doubly effective active systems: as they solve the previously mentioned problems and, moreover, they can harness energy to be used in different applications. The main findings of the existing research on asphalt solar collectors are gathered together in this review paper. Firstly, the main heat transfer mechanisms involved in the solar energy collection process are identified and the most important parameters and variables are presented. After analyzing the theoretical foundations of the heat transfer process, this review focuses on the types of studies carried out so far on asphalt's thermal behavior, different methodologies employed by other authors to study asphalt solar collectors and influence of the variables involved in thermal energy harvesting.

Keywords: asphalt solar collector, heat transfer, asphalt temperature, study methodology, sensitivity analysis.

"Corresponding author. Tel.: +34 942202053; fax: +34 942201703

E-mail address: daniel.castro@unican.es 


\section{Contents}

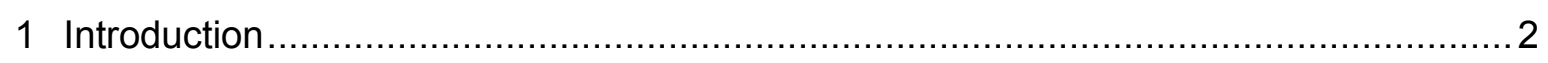

2 Energy balance in asphalt solar collectors ........................................................ 4

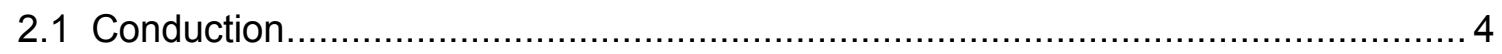

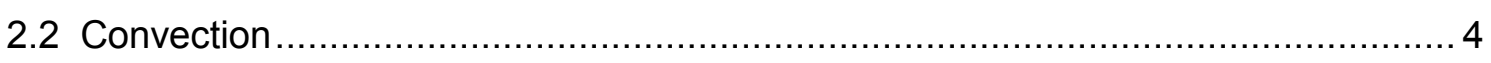

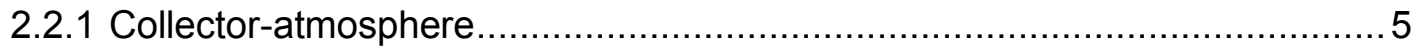

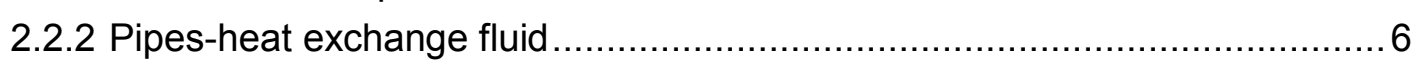

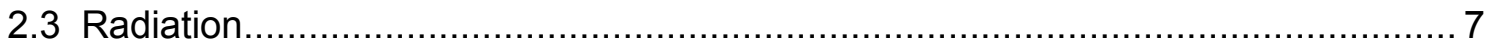

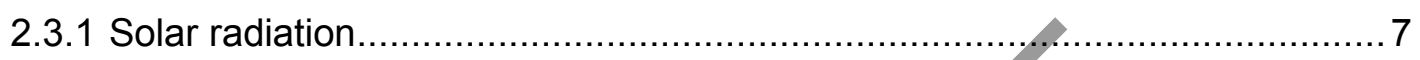

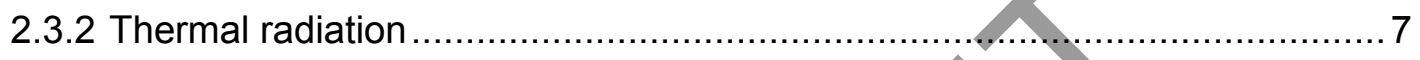

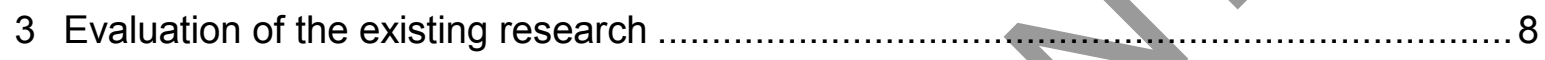

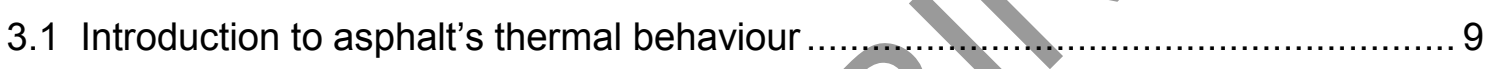

3.1.1 Methods for temperature prediction ................................................. 9

3.1.2 Methods for determining asphalt's thermal properties .............................. 10

3.1.3 Sensitivity analysis of asphalt temperature ....................................... 11

3.2 Study methodology of asphalt solar collectors ................................................ 12

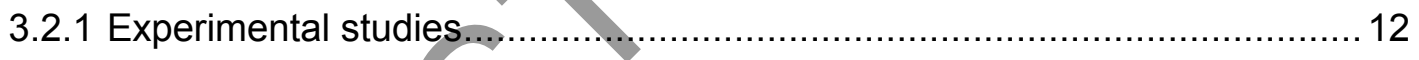

3.2.2 Theoretical approaches: numerical modeling and simulation .................... 13

3.3 Variables involved in thermal energy collection .......................................... 13

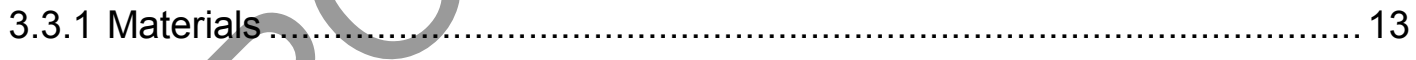

3.3.2 Geometrical and working parameters............................................ 15

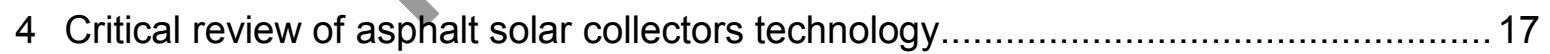

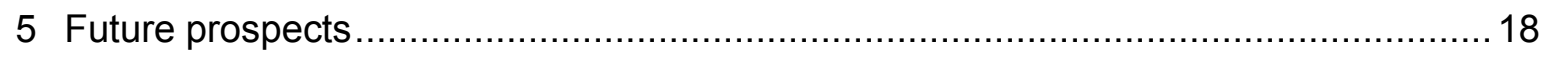

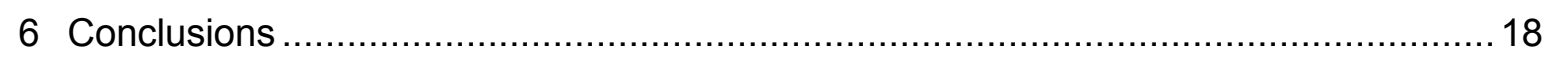

\section{Introduction}

Asphalt pavement surface temperature can reach up to $70^{\circ} \mathrm{C}$ in summer inducing a rise in temperature of the air above, which is generally known as the heat island effect. It causes an increase in power consumption due to the use of air conditioning and a 
decrease in air quality in cities. Moreover, pavements under such high temperatures are prone to suffer from rutting. In particular, the thermal oxidation rate doubles with each 10 $\mathrm{K}$ increment in temperature [1].

Asphalt solar collectors consist of pipes embedded in the pavement with a circulating fluid inside. Solar radiation causes an increase in pavement temperature. Due to the temperature gradient between the fluid circulating through pipes and the pavement, a heat transfer process occurs from pavement to fluid which leads to a drop in pavement temperature and an increase in fluid temperature. This drop in asphalt temperature contributes to mitigate the heat island effect and reduce the risk of permanent deformations. However, what makes asphalt solar collectors really interesting is their ability to use the temperature rise undergone by the circulating fluid to harness energy. Asphalt solar collectors are usually coupled with low temperature geothermal heat pumps, obtaining reasonable efficiency and operating costs. Energy obtained from asphalt solar collectors is generally used for snow-melting systems or to maintain thermal comfort of adjacent buildings. There are also concrete solar collectors, but because of the black color, asphalt's solar absorption coefficient is higher than concrete [2]. As a consequence, asphalt solar collectors perform better than the concrete ones.

The first reference to an asphalt solar collector dates from 1979 and is a patent entitled "Paving and solar energy system and method" [3]. One of the pioneer applications of an asphalt solar collector as a snow-melting system is the Swiss system SERSO. It consisted of pipes embebed in a bridge deck. The system is capable of storing $20 \%$ of the energy irradiated over the bridge in summer. The GAIA system similar to SERSO, installed in 1995 in Ninohe, Japan, was the first to operate automatically [4, 5]. There are several studies on the use of asphalt solar collectors as snow-melting systems $[6,7,8,9$, $10,11]$. On the market, there are companies that commercialize these systems, such as the Dutch Ooms International holding with its Road Energy Systems $®$ (RES) [12] and WinnerWay@ [13]. The English company ICAX TM Ltd has already installed asphalt collectors such as the snow-melting system in Toddington or the Howe Dell School, where the playground is a solar collector that contributes to maintain the thermal comfort inside the building [14]. Other companies, such as Alternatives and Novotech Inc. in collaboration with Worcester Polytechnic Institute have developed a kind of asphalt solar collector called Roadway Power System that combined with a turbine system produces electrical energy [15]. 


\section{Energy balance in asphalt solar collectors}

An asphalt solar collector, where the energy is balanced, is formed by three different material media: two solids, the asphalt pavement and the pipes, and two fluids, the air of the atmosphere and the fluid flowing through pipes.

There are three mechanisms of heat exchange in an asphalt solar collector: exchange by conduction, convection and radiation. The energy is balanced first along the pavement-atmosphere interface. The heat flux through this interface is caused by solar radiation, convection and thermal radiation. This heat flux causes a temperature difference between the asphalt surface and a point located in the pavement at a certain depth, leading to a conduction process from the pavement surface to the interior. At the depth where the pipes are embebed, this heat transfer by conduction continues through the interface pavement-pipe and through the pipe wall. A convection process occurs due to the temperature difference between the interior surface of the pipe and the fluid, causing an increase in fluid temperature.

\subsection{Conduction}

Conduction is the process by which heat is exchanged from one point to another throughout a body due to the temperature gradient between two points. In the asphalt solar collector, heat transfer occurs from the pavement surface to the interior according to Fourier's Law:

$$
q_{n}=-k_{n} \nabla T_{n}
$$

Where $q_{n}\left(W \mathrm{~m}^{-2}\right)$ is the heat transfer rate in $n$ direction by unit of surface perpendicular to $n$ direction; $k_{n}$ is the thermal conductivity in $n$ direction $\left(W m^{-1} K^{-1}\right)$ and $\nabla T_{n}$ is the temperature gradient in $n$ direction $\left(K^{-1}\right)$.

\subsection{Convection}

Convection is a heat transfer process by which heat is transferred between a moving fluid and a solid surface in contact with the fluid. Two different convection processes occur in an asphalt solar collector, one between the asphalt surface and the air above it, and the other between the circulating fluid and the pipe walls. The convection can be forced or natural, depending on the causes that induce the fluid movement and the flow can be laminar or turbulent depending on flow movement conditions. The Reynolds 
number necessary to start turbulent flow in a flat plate is $\operatorname{Re}_{D}=5 \times 10^{5}$. Turbulent flow starts at $\operatorname{Re}_{D} \approx 2,300$ for internal pipe flow, althought a fully developed turbulent flow does not occur till approximately $\operatorname{Re}_{D} \approx 10,000$ [16]. Flow must be turbulent to achieve the maximum heat transfer rate at pipes. Collectors can be designed with pipe diameter and flow rate that ensure turbulent flow inside pipes. In the case of convection between air and pavement surface, the best case scenario is the natural convection to reduce heat losses, but this condition depends on the atmospheric conditions, particularly on wind velocity.

The heat flow by convection is expressed as:

$$
q_{c}=h A_{s}\left(T_{s}-T_{f}\right)
$$

Where $h$ is the mean convection coefficient of the surface $\left(W m^{-2} K^{-1}\right) ; A_{s}$ is the surface area $\left(m^{2}\right) ; T_{s}$ is surface temperature $(K)$ and $T_{f}$ is fluid temperature $(K)$. The mean convection coefficient $h$ is obtained from the adimensional Nusselt number, $\mathrm{Nu}$ :

$$
h=\frac{N u k}{L}
$$

Where $k$ is the material's thermal conductivity $\left(W m^{-1} K^{-1}\right)$ and $L$ the characteristic length $(m)$. The Nusselt number $N u$ is determined using the different empirical correlations depending on the type of convection and the flow regime.

\subsubsection{Collector-atmosphere}

As stated before the convection between collector and atmosphere can be forced or natural. It is natural when there is no wind and the convection is only due to a temperature gradient between asphalt surface and atmosphere. On the contrary, forced convection is caused by wind that creates an air flow over the asphalt surface.

\subsubsection{Natural convection}

- If the warm surface is upwards or the cold surface is downwards:

$$
\begin{aligned}
N u & =0.54 G r_{L} R a^{1 / 4} & 10^{4} \leq R a \leq 10^{7} \\
N u & =0.15 G r_{L} R a^{1 / 3} & 10^{7} \leq R a \leq 10^{11}
\end{aligned}
$$

- If the warm surface is downwards or the cold surface is upwards:

$$
N u=0.27 G r_{L} R a^{1 / 4} \quad 10^{5} \leq R a \leq 10^{10}
$$

Where $R a$ is Rayleigh number and $G r_{L}$ is Grashof number [16].

\subsubsection{Forced convection}


- Laminar flow: If flow is laminar along all the surface or if the transition to turbulent flow occurs at a position such that $0.95 \leq x_{c} / L \leq 1$ :

$$
N u=0.664 \operatorname{Re}_{L}^{1 / 2} \operatorname{Pr}^{1 / 3}
$$

- Turbulent flow: If the turbulent flow conditions occur in a position $x_{c} / L \leq 0.95$ and the critical Reynolds number for starting the transition zone to the turbulent flow is $\operatorname{Re}_{x, c} \leq 5 \times 10^{5}$ then:

$$
N u=\left(0.037 \operatorname{Re}_{L}^{4 / 5}-871\right) \operatorname{Pr}^{1 / 3}
$$

To use the previous correlation the following conditions must be satisfied:

$$
\begin{gathered}
0.6<\operatorname{Pr}<60 \\
5 \times 10^{5}<\operatorname{Re}_{L}<10^{8}
\end{gathered}
$$

Duffie and Beckman (1991) recommended calculating the convection coefficient for both natural and forced convection and choosing the highest value to evaluate convection heat flow [17].

Some research uses the previous correlations to calculate the convection coefficient between the asphalt pavement and air [18,19], but others [20, 21, 22, 23] use empirical correlations developed for asphalt surfaces, such as the following equation:

$$
h_{c}=698.24\left[0.00144 T_{m}{ }^{0.3} u_{m}{ }^{0.7}+0.00097\left(T_{s}-T_{\text {air }}\right)^{0.3}\right]
$$

Where $T_{a i r}$ is the air temperature $(K) ; T_{s}$ is the asphalt surface temperature $(K) ; T_{m}$ is the mean temperature between $T_{a i r}$ and $T_{s}(K)$ that has to be in the interval $6.7-27^{\circ} \mathrm{C}$ and $u_{m}$ is the wind velocity $(\mathrm{m} / \mathrm{s})$ whose value must be in the range from 0.8 to 8.5 [24]. In other correlations, the convection coefficient only depends on wind velocity, as in Jurges' equation:

$$
h_{c}=5.8+4.1 u_{m}
$$

A typical range for the heat transfer coefficient of air is between 17 and $22.7 \mathrm{~W} \mathrm{~m}^{-}$ ${ }^{2} K^{-1}$ [20]. According to Hall et al. (2012), Jurges equation gives the best approximation to the values obtained experimentally.

\subsubsection{Pipes-heat exchange fluid}

The turbulent flow convection coefficient in pipes is calculated using the DittusBoelter equation. The mathematical expression of the Dittus-Boelter equation is:

$$
N u=0.023 \operatorname{Re}_{D}{ }^{4 / 5} \operatorname{Pr}^{n}
$$


The $n$ value is 0.4 if the fluid is being heated and 0.3 if it is being cooled. The Dittus-Boelter equation can be used for small temperature differences, as is the case of the asphalt solar collector, and the following conditions must also be fullfilled:

$$
\begin{gathered}
0.7 \leq \operatorname{Pr} \leq 160 \\
\operatorname{Re}_{D} \geq 10,000 \\
L / D \geq 10
\end{gathered}
$$

\subsection{Radiation}

Radiation is a way of transferring energy via electromagnetic waves which do not require the presence of any material medium. When an electromagnetic wave reaches a solid or liquid surface, the incident wave can be reflected $(\rho)$, absorbed $(\alpha)$ or transmitted $(\tau)$, producing a balance of the incident radiation. As asphalt is an opaque body $(\tau=0)$, all the incident radiation is reflected and absorbed:

$$
\rho+\alpha=1
$$

\subsubsection{Solar radiation}

Part of the radiation coming from the sun is absorbed by the atmosphere before reaching the Earth's surface: as a consequence, only a percentage of solar radiation reaches the asphalt surface. This radiation is called incident radiation. As asphalt is not a perfect black body, part of the incident radiation is reflected, so the solar radiation absorbed by the asphalt surface is calculated from:

$$
q_{s}=\alpha_{s} q_{i}
$$

Where $q_{s}$ is the radiation absorbed by the body $\left(W m^{-2}\right) ; q_{i}$ is the incident solar radiation $\left(W \mathrm{~m}^{-2}\right)$ and $\alpha_{s}$ is the absorptivity of the material to solar radiation.

\subsubsection{Thermal radiation}

The thermal radiation is the type of electromagnetic radiation emitted by bodies because their temperature is above absolute zero $\left(-273^{\circ} \mathrm{C}\right)$. The emissivity $\varepsilon$ is the ratio between the radiation emitted by a body at a certain temperature and the radiation emitted by a black body at the same temperature. The thermal radiation emitted by an asphalt surface is calculated according to Stefan-Boltzmann Law [21, 25]:

$$
q_{r}=\sigma \varepsilon T_{s}^{4}
$$


Where $q_{r}$ is the emitted radiation $\left(W m^{-2}\right) ; \varepsilon$ is the material emissivity; $\sigma$ is the Stefan-Boltzmann constant equal to $5.67 \times 10^{-8} \mathrm{~W} \mathrm{~m}^{-2} \mathrm{~K}^{-4}$ and $T_{s}$ is the surface temperature $(K)$.

Apart from emitting radiation, asphalt surfaces also absorb longwave radiation coming from the atmosphere:

$$
q_{a}=\sigma \alpha_{a} T_{s k y}^{4}
$$

Where $q_{a}$ is the absorbed longwave radiation $\left(W \mathrm{~m}^{-2}\right) ; \alpha_{a}$ is the material absortivity to longwave radiation; $\sigma$ is the Stefan-Boltzmann constant and $T_{s k y}$ is the effective sky temperature $(K)$.

Different approaches are used to determine $T_{s k y}$ : some consider that it is $6 \mathrm{~K}$ lower than the dry bulb air temperature [24]. Although $T_{s k y} \neq T_{\text {air }}$, some research assumes that they are equal $[20,21,26,27]$. The Bliss equation is a correlation widely used to calculate $T_{s k y}$ as a function of the air temperature $T_{a i r}$ and the dew point temperature $T_{d p}[18,19]$ :

$$
T_{s k y}=T_{a i r}\left(0.8+T_{d p} / 250\right)^{0}
$$

According to Hall et al. (2012), the Bliss equation gives the best approximation to the experimentally measured results [24].

Since the radiation from the atmosphere is concentrated about the same spectral region as the surface emission, it can be assumed that $\alpha_{a} \approx \varepsilon$ [16]. With this simplification, the net heat flow due to longwave radiation is:

$$
q_{l}=\sigma \varepsilon\left(T_{s}^{4}-T_{s k y}^{4}\right)
$$

When balancing energy some authors use a coefficient called the combined coefficient of heat transfer that takes into account the effects of convection and longwave radiation [28, 29]. In addition to the conduction, convection and radiation discussed so far, there is a latent and sensible heat flow caused by rainfall not considered in most studies based on energy balance on an asphalt surface [17].

\section{Evaluation of the existing research}

In this section, the existing studies carried out so far on asphalt solar collectors are analyzed. Firstly, a compilation of the different studies of asphalt thermal behavior found in the literature is presented as an introduction. Afterwards, the methodology used to 
study asphalt solar collectors is reviewed. Finally, the influence of some variables involved in the thermal energy collection process is analyzed.

\subsection{Introduction to asphalt's thermal behaviour}

It is necessary to know the temperature distribution of an asphalt pavement subject to solar radiation before studying the asphalt collector behaviour itself. Several authors have developed methods for predicting asphalt temperatures because they significantly affect pavements: high temperatures can cause plastic deformations while lower temperatures can lead to damage by hardening. An account of the studies carried out so far to determine pavement temperature in different regions is provided in section 3.1.1. In almost all asphalt temperature prediction models, asphalt thermal properties are required as inputs, so in section 3.1.2 some existing methods to determine thermal conductivity, heat capacity and thermal diffusivity of asphalt materials are described briefly. Finally, some conclusions of sensitivity studies found in the literature, which analyze the influence of asphalt properties on pavement temperature, are mentioned in section 3.1.3.

\subsubsection{Methods for temperature prediction}

Barber (1957) was among the first to develop a model to calculate the maximum pavement temperature by applying a thermal diffusion model to a semi-infinite medium $[20,21]$. A series of studies to predict the temperatures of asphalt pavements were developed until 1987 based on this first model ranging from empirical correlations: Southgate and Deen 1969, Rumney and Jimenez, 1971, Noss 1973, Thomson and Dempsey 1987; to models based on the equations of energy balance in the asphalt: Straub et al. 1968, Demsey and Thompson 1970, Williamson 1972, Christison and Anderson 1972, Thompson et al., 1987 [17, 18].

The U.S. Strategic Highway Research Program (SHRP) was created in 1987. As a part of it, the Long Term Performance Program (LTPP) was created for in situ characterization of pavements in North America. At the same time, under the LTPP, the SMP (Seasonal Monitoring Program) was created in 1994 to obtain hourly data on state highway pavements in the United States and Canada and to evaluate the influence of temperature and moisture content variations on pavement behavior [18, 24, 37]. It collected data from nearby weather stations and road sections fitted with sensors [17].

One of the studies on the asphalt pavement temperature prediction most often cited was conducted by Solaimanian and Kennedy (1993) in which a method based on 
energy balance on the pavement surface was developed as a tool for SHRP. It is used to quickly and easily calculate the maximum pavement temperature and so to determine the dosage of asphalt mix [20].

Based on the work of Solaimanian and Kennedy (1993), Hermansson (2000) developed a numerical simulation model to calculate the asphalt temperature at different depths during the summer [35]. In 2004 he expanded his model to be able to predict the asphalt temperature in both summer and winter [21].

Yavuzturk et al. (2005) developed a method to predict the transient temperature distribution in asphalt with a bidimensional finite difference model. The model allows different types of asphalt mixtures to be distinguished in both vertical and horizontal directions, which is a big advantage compared to studies based on statistical analysis of observed data [18], such as the correlation developed by Diefenderfer et al. (2006) who tried to estimate the maximum and minimum asphalt temperature at a certain depth by linear regression techniques [37]. At the same time, Minhoto et al. (2005) developed a tridimensional finite element model to calculate the pavement temperature, from hourly solar radiation, mean daily wind speed and hourly air temperature collected at a weather station [22].

Recently Han et al. (2011) and Hall et al. (2012) developed models to calculate the temperatures of pavements in the United States based on the same inputs as Minhoto et al. (2005), but unlike these studies, they used a one-dimensional finite difference approach. Furthermore, Han et al. (2011) studied the variability of asphalt properties in summer and winter as Hermansson did. The Hall et al. (2012) model's accuracy proved to be as good as other complex commercial software using finite elements in $2 D$ or 3D [21, $22,24,35,36]$.

The data obtained from the LTPP were used as a basis to validate many of the models mentioned previously $[18,21,24,36]$. Others have been validated with instrumented sections in other countries such as Portugal [22] and Sweden [21].

\subsubsection{Methods for determining asphalt's thermal properties}

The usual test to determine the thermal conductivity of different materials is established by the ASTM C177 employing a one-dimensional method that calculates conductivity from the steady state. A disadvantage of steady-state methods is that they require flat plates with a thickness-to-length ratio lower than 1:3, which considerably limits the maximum aggregate size of the samples. Besides, obtaining samples from roads with these dimensions deteriorates the pavement structure. Another drawback is the time required to reach the steady state and the accuracy with which the applied heat flow has to be 
measured. In contrast, transient methods require less time to carry out the test and are adaptable to different geometries. Luca and Mrawira (2005) combined stationary and transient methods to calculate thermal conductivity, specific heat and thermal diffusivity from the same test. The conductivity is calculated once the samples reach thermal equilibrium, the thermal diffusivity is obtained in the temperature transient state and specific heat is calculated from the above $[38,39,40]$. Typical values of asphalt surfaces thermal properties are: thermal conductivity is in the range 0.74-2.89 $\mathrm{W} / \mathrm{mK}$ [42], specific heat is in the range 800 to $1853 \mathrm{~J} / \mathrm{Kg} \mathrm{K}$ [38] and thermal diffusivity between 1.2-16.8 $\times 10^{-7}$ $\mathrm{m}^{2} \mathrm{~s}^{-1}[24]$.

Carlson et al. (2010) designed a test to measure thermal conductivity from cylindrical samples such as those used in mechanical laboratory tests achieving thermalmechanical test integration [40]. Nguyen et al. (2012) have gone a step further in the thermal-mechanical test integration. They have been able to determine thermal conductivity, thermal transfer coefficient and specific heat from samples subject to tension-compression cycles [41].

\subsubsection{Sensitivity analysis of asphalt temperature}

Several sensitivity studies have been carried out to determine the influence of the variation of different parameters in asphalt temperature [18, 19, 36, 42]. Some of the conclusions obtained in these studies concerning thermal conductivity, specific heat, albedo and emissivity/absorptivity are cited below.

4.1.3.1 Thermal conductivity. The mean maximum daily temperature and the minimum nightly temperature increase as thermal conductivity rises [19]. Surface temperature decreases with increasing thermal conductivity while temperature rises as depth increases $[20,28,42]$. Temperature is more sensitive to thermal conductivity variations as depth increases [21, 42].

4.1.3.2 Specific heat. Temperature variations decrease as asphalt specific heat increases due to the greater heat storage capacity of the pavement $[18,19]$. This decrease is more noticeable as depth increases because, on the surface, there is no effective heat storage volume. Asphalt pavements with higher specific heat take more time to reach maximal temperatures than pavements with lower capacities [18].

4.1.3.3 Albedo. This is the reflectivity of an asphalt surface $\rho$.The albedo rise causes both daily and nightly temperature decrease. The temperature drop during the night is due 
to the lower energy absorbed during the day [19]. Hermansson (2004) observed that the albedo of an asphalt surface is greater in winter than in summer because, during winter, the asphalt surface may be covered by ice or snow so the asphalt color is lighter causing an increase in the percentage of reflected radiation. Changes from 0.2 in summer to 0.3 or 0.35 in winter were observed [21]. This is confirmed by the earth's surface albedo measured by satellite remote sensing techniques [36].

4.1.3.4 Emisivity/Absorptivity: Small variations in emissivity and absorptivity cause major changes in temperature profile [42]: increasing the emissivity leads to maximal and minimal temperature decrease [19] while increasing the absorptivity makes the surface temperature drop [20]. However, Han et al. (2011) noted that if the algebraic difference between the values of emissivity and absorptivity is constant there are no major changes in pavement temperatures [36]. There is no seasonal variation of absorptivity, unlike what is reported for the albedo [36]. It should be noted that the absorptivity of an asphalt material decreases with time because the dark surfaces subject to solar radiation and atmospheric agents become lighter and reflect more incident solar radiation [1, 24, 43]. Moreover, dirt also helps in reducing the absorptivity values from 0.9 , a typical coefficient of asphalt surfaces, to values of 0.8 [30].

\subsection{Study methodology of asphalt solar collectors}

Study methods found in the literature to analyze the behavior of an asphalt solar collector are based on experimental tests or theoretical studies by means of numerical modeling and simulation.

\subsubsection{Experimental studies}

Experimental studies can be divided into small-scale laboratory tests, small-scale tests under real atmospheric conditions and large-scale tests in asphalt collectors already installed. The last two types of tests provide greater insight into system behavior, because not only the elements that influence the energy harvesting process are considered but also their variation in real conditions, which would be impossible to incorporate during laboratory tests.

Three types of geometries have been used for the experimental tests found in the literature: small cylindrical samples, square slabs and rectangular slabs. Regarding pipe arrangement, it is performed mainly with straight pipes or pipes in a serpentine shape. In 
Table 1 the experimental studies are classified according to the type of test, geometry of the sample and pipe arrangement.

The types of experimental studies that provide greatest understanding of the behavior of the collector are the IASC and the SSRC, because they are subject to real conditions and the geometry is of considerable size, which facilitates the study of heterogeneous materials such as asphalt. On the contrary, when very small specimens are used, their behavior may be affected by some peculiarity of the materials. In addition, it is sometimes difficult to extrapolate the behavior of a reduced scale sample because some variables may not be significant on a small scale but they may be relevant in the real scale solar collector or vice versa. For all the previous reasons, it is necessary to deepen the study of solar collectors by means of IASC or SSRC tests, since the number of them found in the literature is limited.

\subsubsection{Theoretical approaches: numerical modeling and simulation}

The theoretical study of the asphalt solar collector is generally carried out using the finite element method (FEM) $[23,28,29,31,34]$ unlike the thermal study of pavements for which the finite difference method is frequently used (FDM) [8, 19, 20, 21, $24,35,36]$. One of the most widely used commercial software tools for thermal analysis by finite element is ANSYS [22, 28, 29, 34] but there are others such as FEMMASSE [31] or COMSOL [26]. It is important to initially calibrate numerical models with experimental studies and later validate results to verify that the model assumptions and simplifications can be made without major deviations from the results obtained experimentally.

\subsection{Variables involved in thermal energy collection}

In this section, some findings obtained in studies cited in section 3.2 related to materials, geometric parameters and operating conditions of the asphalt solar collector are compiled.

\subsubsection{Materials}

The influence of using different kinds of materials in the asphalt solar collector is analyzed in the following paragraphs.

3.3.1.1 High thermal conductivity aggregates. Several studies have been developed to analyze the influence of raising the pavement thermal conductivity by the addition of aggregates of higher thermal conductivity such as graphite $[10,28,29,33,44]$ or quartz 
$[23,27,32]$. As an idea of the increase in conductivity that the addition of graphite causes, two samples with and without graphite have thermal conductivities of 2.23 and $1.73 \mathrm{~W} \mathrm{~m}^{-1}$ $K^{-1}$ respectively [33]. The results in the studies carried out with and without high conductivity aggregates showed that the addition of aggregates improves the collector efficiency [27, 33]. Mallick et al. (2008) added copper powders trying to increase the conductivity to a greater extent. However, the results were not satisfactory. This might be due to the copper-bitumen interaction during the samples' fabrication process [32].

A steeper temperature gradient occurs in pavement layers with higher thermal conductivity. Moreover, the surface temperature decreases while the temperature with depth increases indicating that the heat transfer process is accelerated by increasing thermal conductivity $[10,28,29,33,44]$.

3.3.1.2 Pipe material. Metallic pipes were used formerly, mainly of steel (43-54 $\left.\mathrm{W} \mathrm{m}^{-1} \mathrm{~K}^{-1}\right)$, iron (80.4 $\left.\mathrm{W} \mathrm{m}^{-1} \mathrm{~K}^{-1}\right)$ or copper $\left(372 \mathrm{~W} \mathrm{~m}^{-1} \mathrm{~K}^{-1}\right)$ due to their high thermal conductivities [45]. Nowadays, plastic pipes are preferred to avoid problems caused by metallic pipe corrosion such as the collapse that occurred in 1997 in a road snow-melting system in Klamath Falls, Oregon [4].

A comparison of four types of pipe materials currently used in radiant heat or snow-melting systems on roads is found the in the literature. It compared pipes of radiant PEX-AL $\left(0.43 W^{-1} K^{-1}\right)$ [46], radiant PEX $\left(0.43 W^{-1} K^{-1}\right)$ [47], radiant ONIX $\left(0.29 \mathrm{~W} \mathrm{~m}^{-1}\right.$ $\left.K^{-1}\right)$ [48] and copper. The highest temperature increase between inlet and outlet was achieved with copper pipes followed by that of radiant PEX-AL with a difference of only $3^{\circ} \mathrm{C}$, which provides an opportunity to use cheaper materials than copper [27]. At the same time, the structural behavior of the asphalt solar collector must be taken into account when selecting a pipe material [28].

3.3.1.3 Heat exchange fluid. The characteristics required for the circulating fluid are: high specific heat, stability in the collector operating temperature range, compatibility with pipes, abundance and low cost. Water is one of the best fluids for systems operating at low temperatures (range from 25 to $90^{\circ} \mathrm{C}$ ) such as asphalt solar collectors [49], but the solidification temperature must be less than the minimum temperature expected at the collector. For this reason mixtures of water and antifreeze are generally used. Glycols are the most commonly used antifreezes due to their moderate cost, high specific heat, low viscosity and ease of corrosion control $[50,51]$.

3.3.1.4 Surface coating. One of the main drawbacks of asphalt as a solar energy collector 
is that its behavior is similar to that of a black body: it absorbs a high percentage of incident solar radiation but in turn it emits thermal longwave radiation at high rates. For this reason Mallick et al. (2008) applied a surface coating consisting of a black painting to reduce asphalt reflectivity. The results showed an increase in collector efficiency although the thermal emission rate is still high [32].

\subsubsection{Geometrical and working parameters}

In the following paragraphs the influence of some geometrical and working parameters, such as pipe diameter, pipe spacing, pipe depth, pipe arrangement and flow rate, on asphalt solar collector performance is analyzed.

3.3.2.1 Pipe diameter. Flow conditions depend strongly on pipe diameter. The heat transfer coefficient for a turbulent flow inside a pipe according to the Dittus-Boelter correlation decreases with increasing diameter if the flow is assumed constant. For the diameters analyzed in the Wang et al. (2010) model, there is no circulating water temperature change, but the increase in diameter causes a drop in pavement surface temperature [28].

3.3.2.2 Pipe spacing. In general, as pipe density per area of solar collector increases the heat collection capacity rises [28,31] and the outlet fluid temperature decreases [31]. However, if pipe spacing lower than the minimal spacing which ensures no cool zones formation between pipes were used the collector efficiency would decrease drastically. This minimal spacing depends on pipe diameter and flow rate [23]. Economic criteria must also be considered when selecting a tube spacing [31].

3.3.2.3 Pipe depth. A thermal gradient with depth occurs in any asphalt surface subject to solar radiation. Due to convection between asphalt and the environment, the maximum temperature of the asphalt surface is located at a certain depth (20 $\mathrm{mm}$ deep according to LTPP) which is optimal for placing the pipes [26]. The pavement temperature distribution becomes more homogenous as pipe depth increases but the amount of energy that the system is able to harness decreases [30,31]. A more uniform temperature distribution can be achieved at lower depths by decreasing pipe spacing [31].

3.3.2.4 Pipe arrangement. This is one of the most important variables concerning a solar collector's performance. No specific studies on asphalt solar collector pipe arrangements have been found so, in this section conclusions obtained from studies on fluid mechanics 
of flat plate collectors are presented. There are two types of pipe arrangements that can be used in an asphalt collector: a network of pipes arranged in parallel (PTC) and arranged in a serpentine fashion (STC). For maximum efficiency, a uniform flow throughout the system has to be mantained, because due to non-uniformities the efficiency can drop by 2-20\% [52]. Several authors have analyzed fluid mechanics in solar collectors [53, 54, 55, 56]. In particular, Matrawy and Farkas (1997) made a comparison between different types of pipe arrangements. The STC proved more efficient than the PTC for several reasons: in the STC the flow rate along the entire pipe is greater enhancing heat transfer between circulating fluid and pipe wall, on the contrary, in the PTC the flow in the connections far from the entrance of water is very low, which impedes the heat transfer process and the existence of a uniform flow. Despite the advantages of the STC versus the PTC, the latter is more common from the commercial point of view [55].

3.3.2.5 Flow rate. The study of flow rate is essential to understand the behavior of an asphalt solar collector, due to the close relationship between flow rate and system efficiency. From the analysis of the influence of flow rate conducted in different studies found in the literature, the following conclusions can be drawn:

- Surface temperature decreases as flow rate increases [10].

- The increase in flow rate has no noticeable influence on temperature profile with depth [10].

- Increasing flow rate, for the same pipe diameter, causes an increase in fluid velocity which leads to an increase in the heat transfer coefficient and the amount of energy that can be harnessed $[10,57]$.

- As flow rate increases, the temperature increment of the water circulating through the asphalt solar collector decreases $[10,33,32,57,31]$ and a longer pipe will be required for the fluid to reach the temperature of pavement at a certain depth [23].

- As flow rate increases, the time required for the solar collector to reach steady state conditions decreases. This time is not influenced by the inlet water temperature [10]. 


\section{Critical review of asphalt solar collectors technology}

The aim of this section is to study the feasibility of the implementation of asphalt solar collectors and make a comparasion with other technologies used for solar energy harvesting.

The good performance of asphalt solar collectors has been demonstrated with real systems installed in different places all around the world with different climatic conditions: Switzerland (SERSO system [4]), Japan (GAIA system [5]), Netherlands (Road Energy Systems ${ }^{\circledR}$ [12] and WinnerWay@ [13]), England (ICAX TM Ltd [14]), China [8], Spain [11] or United States [23].

Compared with concrete pavement solar collectors, asphalt performs better because in spite of having a lower thermal conductivity and heat storage capacity than concrete pavements, asphalt surfaces are able to capture more solar energy because their solar absorption coefficient is higher than the coefficient of concrete pavements due to the black color of asphalt mixtures [2, 4]. One drawback of using asphalt instead of concrete is that during the construction process the high temperature of the hot mix asphalt can cause damage to the pipe system [4].

An issue that has to be considered in the construction of both, asphalt and concrete solar collectors, is the structural response of the system. It is clear that this kind of solar collectors can not be constructed in roads subjected to high traffic intensities or high traffic loads, because the pipe system could be damaged due to a stress concentration. Different studies concerning structural response of pavement solar collectors are found in the literature $[31,58]$.

An advantage of asphalt solar collectors is that they can be installed not only during the construction of new infraestructures but also during the maintenance works, for example, roads are subjected to periodically rebuilt works, a moment when the solar collector system can be installed.

Asphalt solar collectors can be considered economically feasible from the initial investment point of view because two main reasons: the cost of the materials is cheaper than the materials used in a convetional solar collector and the asphalt surface can be used for other purposes. Asphalt surfaces performs as roads, playgrounds, bridges...and at the same time they can be used to collect solar energy, what reduces even more the cost associated to the collector itself, while conventional solar collectors are used just for solar energy harvesting, but, on the contrary, the asphalt solar collectors's efficiency is clearly lower than the efficiency of conventional solar collectors because asphalt collectors are not specifically designed for solar energy harvesting. So, in addition to the initial investment, the operational cost of the whole system, including the heat pump device 
usually coupled with solar thermal collectors, must be carefully analyzed and compared with conventional solar collectors to stablish the economic feasibility of asphalt solar compared with other technologies.

\section{Future prospects}

Regarding the study of the methodology reported in the literature, further testing with larger samples subject to actual weather conditions is considered necessary, since most of the current studies are conducted in laboratory and are based on samples which are too small. Moreover, there are few numerical simulations of asphalt solar collectors that allow a more comprehensive study of the design parameters. There are certain issues that are not covered by the existing methodology: most studies use water as the circulating fluid, but in real systems a mixture of water and antifreeze is generally used. Few investigations have taken into account how moisture or runoff affects the performance of an asphalt solar collector, and the influence of the degree of compaction, or construction method on the asphalt solar collector efficiency has not been discussed.

Almost no references to analyze the influence of using different pipe diameters in collectors efficiency are found in literature. Most of the studies consider the influence of design variables in the system performace individually, but a complete study of the combined influence of several design variables is considered necessary.

A comparison of efficiency, initial investment, maintenance cost, operating cost and life span of asphalt solar collectors versus conventional solar thermal collectors is considered necessary in order to establish the advantages and disadvantages of asphalt solar collectors.

\section{Conclusions}

Research projects carried out and solar collectors already installed confirm the system's ability to reduce the temperature of the asphalt pavement and capture the thermal energy for different purposes: snow-melting systems, air conditioning of buildings or even electric energy production; proving that asphalt solar collector systems are able to harness clean and renewable energy from the sun.

As a summary of all the issues discussed in section 3 the following findings can be drawn:

- Asphalt temperature is very sensitive to the variation of the absorptivity. 
- The variation of asphalt thermal conductivity affects the temperature with increasing depth, without producing noticiable changes in surface temperature.

- Copper is the material used in the pipe network which achieves greatest efficiency of the system.

- Both the spacing between pipes and the depth where they are located strongly influence the temperature distribution in the collector. To achieve the maximum efficiency, the flow regime inside the pipes must be turbulent, so pipe diameter and flow rate must be carefully chosen to achieve turbulent flow conditions.

- The optimal pipe arrangement from the thermal point of view is the serpentine arrangement.

- The collector efficiency depends strongly on flow rate: as flow rate increases, heat transfer between the fluid and the pipe increases, but the temperature increment undergone by the fluid decreases.

Further investigation on asphalt solar collectors is needed to analyze the influence of some variables not considered in the existing studies and to compare the performance and associated costs of this technology versus conventional solar thermal collectors.

\section{References}

[1] Berdahl P, Akbari H, Levinson R, Miller WA. Weathering on roofing materials- an overview. Construction and Building Materials 2006; 22 (4): 423-433.

[2] Larsson $\mathrm{O}$, Thelandersson $\mathrm{S}$. Estimating extreme values of thermal gradients in concrete structures. Materials and Structures 2011; 44: 1491-1500.

[3] Lowe JL. 1979. Paving and solar energy system and method. Inventor: Wendel, I.L. United States, patent of invention US 4.132.074, 01-02-1979.

[4] Lund JW. Pavement snow melting. Geo-Heat Center, Oregon Institute of Technology, Klamath Falls, OR. Available at: http://geoheat.oit.edu/pdf/tp108.pdf [Accessed 11 April 2012]

[5] Gao Q, Huang Y, Li M, Liu Y, Yan YY. Experimental study of slab solar collection on the hydronic system of road. Solar Energy 2010; 84: 2096-2102.

[6] Zhao J, Wang H, Chen Z, Qu H. Seasonal behavior of pavement in geothermal snowmelting system with solar energy storage. Transactions of Tianjin University 2006; 12 (5): 319-324.

[7] Liu X, Rees SJ, Spitler JD. Modeling snow melting on heated pavement surfaces. Part I: Model development. Applied Thermal Engineering 2007; 27(5-6): 1115-1124.

[8] Tu Y, Li J, Guan C. Heat transfer analysis of asphalt concrete pavement based on snow melting. International Conference on Electrical and Control Engineering (ICECE) 2010; Wuhan, China, 25-27 June: 3795-3798.

[9] Tu Y, Jiang W, Guan C. Heat analysis of asphalt concrete pavement based on snow melting. International Conference on Electric Information and Control Engineering (ICEICE) 2011; Wuhan, China, 15-17 April: 2225-2228. 
[10] Wu S, Chen M, Zhang, J. Laboratory investigation into thermal response of asphalt pavements as solar collector by application of small-scale slabs. Applied Thermal Engineering 2011; 31: 1582-1587.

[11] Muñoz D. Proyecto Geovial: instalación de un sistema de deshielo mediante intercambio geotérmico y almacenamiento subterráneo (BTES). II Congreso de energía geotérmica en la edificación y la industria 2011; Madrid, Spain, 10-11 March.

[12] http://www.ooms.nl/en/7/301/road energy system.aspx [Accessed 21 December 2011]

[13] http://www.winnerway.nl/sites/wat doen wij.html [Accessed 28 March 2012]

[14] http://www.icax.co.uk [Accessed 21 December 2011].

[15] Novotech, Inc. Roadway power system: technical analysis for thermal energy generation. 2008.Available

at:http://www.masstech.org/Project\%20Deliverables/Alt\%20Unlimited\%20FS\%20Final. pdf [Accessed 28 March 2012]

[16] Incropera FP, Dewitt DP. Fundamentos de transferencia de calor. $4^{\text {th }}$ ed. Naucalpan de Juárez, México : Prentice Hall Hispanoamericana,cop.;1999

[17] Yavuzturk C, Ksaibati K. Assessment of temperature fluctuations in asphalt pavement due to thermal environmental conditions using a two-dimensional, transient finitedifference approach. Mountain Planes Consortium Report, 2002; MPC 02-136. Available at: http://ntl.bts.gov/lib/13000/13100/13135/MPC02-136.htm [Accessed 11 April 2012]

[18] Yavuzturk C, Ksaibati K, Chiasson AD. Assessment of temperature fluctuations in asphalt pavement due to thermal environmental conditions using a two-dimensional, transient finite-difference approach. Journal of Materials in Civil Engineering 2005; 17(4): 465-475.

[19] Gui J, Phelan PE, Kaloush KE, Golden JS. Impact of pavement thermophysical properties on surface temperatures. Journal of Materials in Civil Engineering 2007; 19 (8): 683-690.

[20] Solaimanian M, Kennedy TW. Predicting maximum pavement surface temperature using maximum air temperature and hourly solar radiation. Transportation Research Record 1993; 1417: 1-11.

[21] Hermansson A. Mathematical model for paved surface summer and winter temperature: comparison of calculated and measured temperatures. Cold Regions and Science and Technology 2004; 40: 1-17.

[22] Minhoto M, Pais J, Pereira P, Picado-Santos L. Predicting Asphalt Pavement Temperature with a Three-Dimensional Finite Element Method. Journal of the Transportation Research Board 2005; 1919 (1): 96-110.

[23] Mallick, RB, Chen B, Bhowmick S. Harvesting energy from asphalt pavements and reducing the heat island effect. International Journal of Sustainable Engineering 2009; 2 (3): 214-228.

[24] Hall MR, Dehdezi PK, Dawson AR, Grenfell J, Isola R. Influence of the thermophysical properties of pavement materials on the evolution of temperature depth profiles in different climatic regions. Journal of Materials in Civil Engineering 2012; 24 (1): 32-47.

[25] Iordanau G. Flat-Plate Solar Collectors for Water Heating with Improved Heat Transfer for Application in Climatic Conditions of the Mediterranean Region. Doctoral thesis, Durham University 2009. Available at Durham E-Theses Online: http://etheses.dur.ac.uk/174/ 
[26] Chen B, Rockett L, Mallick RB. A laboratory investigation of temperature profiles and thermal properties of asphalt pavements with different subsurface layers. Journal of the Association of Asphalt Paving Technologists 2008; 77: 327-360.

[27] Mallick, RB, Chen B, Bhowmick S. Reduction of urban heat island effect through harvest of heat energy from asphalt pavements. Available at http://heatisland2009.Ibl.gov/docs/211420-mallick-doc.pdf. [Accessed 28 March 2012].

[28] Wang H, Wu S, Chen M, Zhang Y. Numerical simulation on the thermal response of heat-conducting asphalt pavements. Physica Scripta 2010; 139.

[29] Wu S, Wang H, Chen M, Zhang Y. Numerical and experimental validation of full depth asphalt slab using capturing solar energy. 4th International Conference of Bioinformatics and Biomedical Engineering 2010; Chengdu, China, 18-20 June: 1-4.

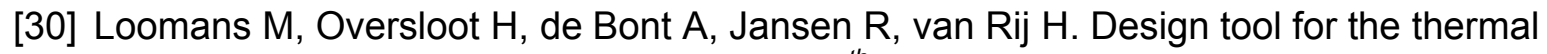
energy potential of asphalt pavements. $8^{\text {th }}$ International IBPSA Conference 2003; Eindhoven, Netherlands, 11-14 August.

[31] Bijsterveld WT, Houben LJM, Scarpas A, Molenaar, AAA. Using Pavement as Solar Collector. Effect on pavement temperature and structural response. Transportation Research Record 2001; 1778 (17): 140-148.

[32] Mallick RB, Chen B, Bhowmick S, Huken MS. Capturing solar energy from asphalt pavements. Draft Paper submitted to the International Society of Asphalt Pavements, 2008. Available at http://users.wpi.edu/ rajib/Pavement\%20Energy-ISAPAugust\%202008.pdf [Accessed 28 March 2012]]

[33] Wu S, Chen M, Wang H, Zhang Y. Laboratory study on solar collector of thermal conductive asphalt. International Journal of Pavement Research and Technology 2009; 2 (4): 130-136.

[34] Chen M, Wu S, Wang H, Zhang J. Study of ice and snow melting process on conductive asphalt solar collector. Solar Energy Materials \& Solar Cells 2011; 95 (12): 3241-3250

[35] Hermansson A. Simulation model for calculating pavement temperatures including maximum temperature. Journal of the Transportation Research Board 2000; 1699: 134-141.

[36] Han R, Jin X, Glover CJ. Modeling pavement temperature for use in binder oxidation models and pavement performance prediction. Journal of Materials in Civil Engineering $2011 ; 23(4): 351-359$.

[37] Diefenderfer BK, Al-Qadi IL, Diefenderfer SD. Model to predict pavement temperature profile: development and validation. Journal of Transportation Engineering 2006; 132 (2): 162-167.

[38] Luca J, Mrawira DM. Thermal properties and transient temperature response of fulldepth asphalt pavements. Transportation Research Record 2002; 1809 (1): 160-171.

[39] Luca J, Mrawira DM. New measurement of thermal properties of superpave asphalt concrete. Journal of Materials in Civil Engineering 2005; 17(1): 72-79.

[40] Carlson JD, Bhardwaj R, Phelan PE, Kaloush KE, Golden JS. Determining thermal conductivity of paving materials using cylindrical sample geometry. Journal of materials in civil engineering 2010; 22(2): 186-195.

[41] Nguyen QT, Benedetto H, Sauzéat C. Determination of thermal properties of asphalt mixtures as another output from cyclic tension-compression test. Road Materials and Pavement Design 2012; iFirst: 1-19. 
[42] Solaimanian M, Bolzan P. Analysis of an integrated model of climate effects on pavements. Strategic Highway Research Program, 1993; report SHRP-A-637. Available at: http://onlinepubs.trb.org/onlinepubs/shrp/SHRP-A-637.pdf [Accessed 11 April 2012]

[43] American Concrete Pavement Association. Albedo: a mesure of pavement surface reflectance.2002. Available at www.acpa.org/Downloads/RT/RT3.05.pdf [Accessed 15 March 2012]

[44] Chen M, Wu S, Zhang Y, Wang H. Effects of conductive fillers on temperature distribution of asphalt pavements. Physica Scripta 2010; 139: 1-5.

[45] Bejan A, Kraus A. Heat transfer Handbook. John Wiley \& Sons 2003. Available at:http://www.knovel.com/web/portal/browse/display? EXT KNOVEL DISPLAY booki $\mathrm{d}=725 \&$ Verticall $\mathrm{D}=0$ [Accessed 28 March 2012]

[46] http://www.ardipex.com/pex-al-pex-main-characteristics.php

[47] Chiasson A. Design and installation of a new downhole heat exchanger for direct use space heating. GHC Bulletin; Marzo 2005: 20-24. Available at: http://geoheat.oit.edu/bulletin/bull26-1/art6.pdf [Accessed 28March 2012].

[48] http://ecomfort.com/products/watts-radiant-onix-radiant-tubing-spool-12-x-400/2464 [Accessed 28 March 2012]

[49] Hasnain SM. Review on sustainable thermal energy storage technologies, Part I heat storage materials and techniques. Energy Conversion and Management 1998; 39 (11): 1127-1138.

[50] Zwarycz K. Snow melting and heating systems based on geothermal heat pumps at Goleniow airport, Poland. The United Nations University Geothermal Training Programme Reports 2002; 21: 431-464. Available at: http://www.os.is/gogn/unu-gtpreport/UNU-GTP-2002-21.pdf [Accessed 28 March 2012].

[51] Wang H, Qi C. Performance study of underground coupled heat pump for residential buildings. Energy and Buildings 2008; 40: 1278-1286.

[52] Chiou JP. The effect of nonuniform fluid folow distribution on the termal performance of solar collector. Solar Energy 1982; 29 (6): 487-502.

[53] O'Keefe MJ, Francey JLA. The effect of the flow distribution on the thermal efficiency of a solar collector. Aust. J. Phys 1986; 39: 945-59.

[54] Abdel-Khalik SI. Heat removal factor for a flat-plate solar collector with a serpentine tube. Solar Energy 1976; 18: 59-64.

[55] Matrawy KK, Farkas I. Comparison study for thre types of water collectors for water heating. Energy Conversion Management 1997; 38 (9): 861-869.

[56] Molero N, Cejudo JM, Domínguez F, Rodríguez E, Carrillo A. Numerical 3-D heat flux simulations on flat plate solar collectors. Solar Energy 2009; 83: 1086-1092.

[57] Yan L, Qing G, Yong H. Modeling Hydronic Solar Collection on Slab of Road and Bridge and a Feature Study. ICEET '09 International Conference on Energy and Environment Technology 2009; Guilin, Guangxi, China, 16-18 October: 733-73

[58] Bijsterveld WT and de Bont AH. Structural Aspects of Asphalt Pavement Heating and Cooling Systems. . $3^{\text {rd }}$ International Symposium on 3D Finite Element Modeling, Design and Research 2002; Amsterdam, Netherlands, 2-5 April. 
Table 1. Classification of experimental studies found in literature.

\begin{tabular}{|c|c|c|c|c|c|c|c|c|c|c|}
\hline Reference & $\begin{array}{l}\text { Type of } \\
\text { study }\end{array}$ & $\begin{array}{l}\text { Type of } \\
\text { Geometry }\end{array}$ & $\begin{array}{c}\text { High } \\
\text { cond. } \\
\text { aggregate }\end{array}$ & Pipes material & Fluid & $\begin{array}{l}\text { Surface } \\
\text { coating }\end{array}$ & $\begin{array}{c}\text { Internal } \\
\text { diameter } \\
(\mathrm{mm})\end{array}$ & $\begin{array}{l}\text { Pipe } \\
\text { spacing } \\
(\mathrm{mm})\end{array}$ & $\begin{array}{l}\text { Pipe } \\
\text { depth } \\
(\mathrm{mm})\end{array}$ & $\begin{array}{c}\text { Pipe } \\
\text { arrangement }\end{array}$ \\
\hline [30] & $\mathrm{IASC}^{\mathrm{a}}$ & $16.4 \mathrm{~m}^{2}$ & No & - & water & No & - & 150 & 135 & PA2 \\
\hline [31] & IASC & $2.4 \times 3.5 \mathrm{~m}$ & No & polyethylene & - & No & 20 & 300 & 70 & - \\
\hline \multirow{2}{*}[23,27,32]{} & $L A B^{b}$ & $\begin{array}{c}C^{\mathrm{d}} \text { (diameter } \\
150 \mathrm{~mm}, \text { height } \\
100 \mathrm{~mm})\end{array}$ & Yes/No & copper & water & Yes/No & - & - & - & $\mathrm{PA} 1^{\mathrm{g}}, \mathrm{PA} 2^{\mathrm{h}}$ \\
\hline & $\mathrm{SSRC}^{\mathrm{C}}$ & $\begin{array}{c}\mathrm{RS}^{\mathrm{e}} 1.8 \times 0.9 \mathrm{x} \\
0.125 \mathrm{~m}\end{array}$ & No & copper & water & No & - & - & 50 & Other \\
\hline [27] & LAB & $\begin{array}{c}\text { RS } 1.8 \times 0.9 x \\
0.3 \mathrm{~m}\end{array}$ & No & $\begin{array}{c}\text { copper, radiant } \\
\text { PEXAL, radiant } \\
\text { ONIX, radiant PEX }\end{array}$ & water & No & - & - & 40 & PA1 \\
\hline$[29,33]$ & LAB & $\begin{array}{c}\mathrm{SS}^{\mathrm{f}} 300 \times 300 \mathrm{x} \\
150 \mathrm{~mm}\end{array}$ & Yes & copper & water & No & 15 & 100 & 75 & PA2 \\
\hline [10] & LAB & $\begin{array}{c}\text { SS } 300 \times 300 x \\
150 \mathrm{~mm}\end{array}$ & Yes & - & water & No & & 100 & 75 & PA2 \\
\hline
\end{tabular}

${ }^{a}$ IASC: Instrumented Asphalt Solar Collector.

${ }^{b}$ LAB: Laboratory

${ }^{c}$ SSRC: Small Scale Real Conditions

${ }^{d} \mathrm{C}$ : Cylindrical

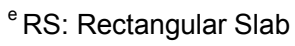

${ }^{f}$ SS: Square Slab

${ }^{g}$ PA1: Straight Pipe

${ }^{\text {h }}$ PA2: Serpentine Pipe 